\title{
El Autorretrato Femenino: Búsqueda De Comprensión Del Sí Mismo.
}

\author{
Dr. Alfredo Zárate Flores \\ Dra. Natalia Gurieva \\ Universidad de Guanajuato
}

\begin{abstract}
This article presents a reflection on some of the most important aspects of creative expression of the woman photographers in the practice of contemporary symbolicself-portraite. The intention of this work is to show how photographers validate their existential condition and operate discourses that validate how they perceive themselves in a social and personal context. As we have seen, this assessment involves the creation of a mechanism to validate the experience and the construction of a symbols that allow establishing a narrative in which women are developing a figuration that prove their abilities in professional, personal and intellectual level.
\end{abstract}

Keywords: Self-portaite; Figuration, Experience, Identity; Feminidad.

Quien se ha acercado al estudio de las formas de figuración en el arte puede comprender que estas se ponen frente a nosotros como la expresión de una condición existencial en la que se esboza el devenir de un autor y la fijación de esa experiencia que soporta el pensamiento y se vuelve, por su acción simbolizadora, objeto y mostración de una idea que se fija para ser mecanismo de la construcción de una identidad. En este sentido, el autorretrato contemporáneo se transfigura y es consciente de la urgencia que le impone su estancia mientras se extiende, sin descanso, en cada obra.

En este trabajo pensamos que en toda obra opera lo que podemos llamar la respuesta del Ser que se manifiesta como estancia de la identidad. Consideramos que el centro desde el que surge la expresión autorrepresentativa es la búsqueda del significado de la existencia de un Yo que toma diversas voces de su historia, de su tiempo, del contenido de su expresión óntica. Si tal como lo afirma Fernando Broncano en Sujetos en la niebla: Narrativas sobre la identidad (2013):

[...] la experiencia es un proceso en el que se entremezcla lo activo y lo pasivo, la espontaneidad y la obediencia es algo que tiene que ver con la idea de que un sujeto es un ser esencialmente individual al que se le aparecen las cosas de una cierta forma, y que, como sujeto, está definido precisamente por la individuación que le dan sus experiencias privadas (Broncano, 2013, pág. 46).

Si esto es cierto, el autorretrato es el espacio donde dicha experiencia se revela mientras se oculta y gracias a él es posible, tal como lo afirma Martin Heidegger, des-ocultar el Ser.

Paul Ricoeur considera que en la existencia humana se promueve un dialogo permanente con un mundo configurado históricamente y cuyo resultado es la construcción de una identidad en constante cambio y capaz de encontrar diversas estancias en su devenir.

Nosotros consideramos que el autorretrato es la expresión de esa estancia que se encuentra o en la que el sujeto se identifica como un yo vinculado a una condición específica. De este modo, el autorretrato aparece como una tarea afín a la respuesta sobre la existencia y sobre los modos en que ésta se da en el horizonte del sujeto.

A este respecto, y hablando específicamente de la literatura, Fernando Broncano considera que: [...] si el modelo de texto es el modelo de acción humana en tanto que se organiza en unidades objetivas a las que solamente se puede acceder a través de la mirada fría del experto en tercera persona, ese mismo modelo demanda un momento de lectura para que el texto se encarne y adquiera sentido (pág. 46).

Nosotros creemos que esa misma condición se revela en el autorretrato porque, en él, no leemos un hecho histórico personal sino que asistimos al otorgamiento de sentido de esa experiencia y de su contexto histórico. Por el autorretrato nos hacemos contemporáneos del agente de la figuración a la que asistimos. 
En el ámbito de la existencia el Da-sein designa el espacio donde se despliega el ser: el lenguaje. El hombre puede revelarse a sí mismo desde la temporalidad que habita y el sentido que in situ da a su existencia. Martín Heidegger afirma en El arte y el espacio (2007), respecto de la plástica que: [...] las figuras plásticas son cuerpos. Su masa, compuesta de diferentes materiales, está configurada de múltiples maneras. La configuración acontece en la delimitación, entendida como inclusión y exclusión con respecto a un límite. Aquí es donde entra en juego el espacio. El espacio es ocupado por la figura plástica y queda moldeado como volumen cerrado, perforado y vacío. Cosa bien sabida y, sin embargo, enigmática (Heidegger, 2009, pág. 13).

Nosotros creemos que, en el caso específico de la imagen fotográfica vinculada al autorretrato, el límite que, a un tiempo, excluye e incluye al sujeto es la experiencia en la que acontece o se configura la identidad que nos es presentada.

Ante esta condición existencial del sujeto consideramos que es posible observar la aparición de la obra figurativa como expresión de una condición existencial que se hace manifiesta del mismo modo en que Heidegger define el Da-sein y en la que se revela la verdad cuando se pone en obra la obra de arte y vincula, en la construcción de la identidad y la expresión del pensamiento, la condición histórica del productor de la imagen: la seña distintiva de un pensamiento que se extiende revelando el sentido del pensar del fotógrafo. Fernando Broncano se refiere a esta expresión del pensar y su actividad hermenéutica como una comprensión que "se convierte entonces en un acto de apropiación del sentido mediatizado por los signos de la cultura en la que habita y que constituyen al sujeto" (Broncano, 2013, pág. 65).

Según Paul Ricoeur, la hermenéutica contemporánea presenta un doble movimiento; uno que va desde la hermenéutica general con una importante base epistemológica y otro que va de la epistemología a la ontología en una dirección de radicalización de la hermenéutica. Ricoeur propone una tercera alternativa en la cual se producirá una dialéctica entre la ontología de la comprensión y la epistemología de la hermenéutica que supera la dicotomía explicación-comprensión y afirma que ambos momentos se requieren mutuamente y son, en el fondo, indisolubles. Ricoeur suscribe al respecto, con algunos matices, la pretensión heideggeriana de disponer jerárquicamente, en distintos planos de originariedad, la interpretación temporal de la constitución originaria del Dasein y asocia cada una de estas esferas con uno de los aspectos distintivos de la narratividad.

Ricoeur afirma el carácter temporal de la existencia humana pero rechaza la ruptura de Heidegger con la metafísica y su pretensión de finalizar la historia del Ser. Sin embargo cree, como Heidegger, que nuestro conocimiento subjetivo sólo puede alcanzar su identidad a través del lenguaje y nosotros agregamos de cualquier lenguaje. Por esta razón, Ricoeur escoge la narrativa como un lugar privilegiado en el establecimiento de una experiencia temporal inherente a la ontología del Da-sein y defiende la idea de que la función poética del lenguaje ignora la función referencial.

El protagonista de la acción figurativa es el ser en el mundo, este adquiere un sentido pleno cuando afronta su ser en la figuración de sus actos y la inscripción en la diacronía de la representación. La identidad se basa en el valor cohesivo de la imagen en su capacidad para forjar una unidad de sentido que trascienda la mera progresión de la historia. Sólo cuando la persona cuenta con su tiempo parece estar en condiciones de contar consigo mismo, con su propia ipseidad, porque el Da-sein sólo existe al proyectarse hacia las posibilidades configuradas por la totalidad de la trama que se manifiesta, en el caso del autorretrato en la figuración que hace de sí mismo el fotógrafo.

Según Paul Ricoeur, la narratividad explora sus propios límites y se encuentra con su insuficiencia cuando el relato no puede ser la representación del todo y se enfrenta a la necesidad de encontrar una figura narrativa que permita pensar otro tiempo y posea una performance que le permita manifestarse como otro en una instancia temporal. Dicha experiencia temporal se expresa como un almacén memorístico que tiene vínculos permanentes con la existencia y permite identificar agencias en la imagen. De este modo, la comprensión del sujeto aparece por aquello que Fernando Broncano define como un juego entre «distancia y extrañamiento» por el que el Yo se reconoce mientras se encuentra en la imagen producida, "en una estructura textual que debe ser primero «explanada», organizada, manejada en términos objetivos y, segundo, «apropiada», hecha carne propia". (Broncano, 2013, pág. 67).

La importancia del recuerdo y el ejercicio de la memoria que lo anterior supone nos ofrece la posibilidad de vincular al agente del autorretrato con su condición histórica y el reconocimiento de su existencia, de su devenir in situ. 
De este modo, Ricoeur acepta la co-participación del tiempo y la historia en la memoria y hace aparecer el límite de los horizontes en los que la existencia se hace presente, gracias a los cuales, se le puede examinar desde la condición histórico-temporal con la adherencia al espacio en el que el sujeto se encuentra.

La relación con el agente en el trascurso del actuar humano puede evitar lagunas de dimensiones temporales importantes que enriquecen tanto la aproximación de la identidad de la persona como la capacidad del sujeto de verse reflejado a sí mismo frente al mundo. La constitución figurativa de la identidad se basa en la manifestación de la comprensión de la experiencia del sujeto. De este modo, según lo hace notar Fernando Broncano:

El sujeto se convierte en parte del flujo de lo real, en receptor del flujo de lo real, en receptor de propiedades que tienen que ver con el mundo. Es cierto que el que ello conduzca a propiedades «finales», como son las que fija la experiencia es parte de la espontaneidad del sujeto en el mundo, pero eso no impide que las experiencias, incluso las ilusiones sean ellas mismas procesos reales y que solo por ello, el sujeto puede convertirse en sujeto epistémico (Broncano, 2013, pág. 19).

Queremos hacer notar que, al confrontar la identidad de las complejidades que se pueden presentar en el acto narrativo y llegar a un punto donde no se pueda avanzar en la descripción de la constitución de la acción como experiencia y desarrollar, por ella, el estudio de sí mismo, se buscaran rasgos característicos de identidad que permitan anticipar la posible limitación de la memoria en un campo práctico y relajado. Lo anterior, nos conduce a desarrollar conexiones entre el tiempo y la historia que acerquen la vida a la imagen autor representacional en el que aparece una versión propia de la plantación de la cuestión sobre la permanencia del Yo en el tiempo y su vinculación con el horizonte histórico al que definimos en tanto espacio y límite de la experiencia que deviene sujeto. Broncano se refiere a esta condición diciendo que "el espacio dentro del cual la figura plástica (autor) se puede encontrar de antemano como un objeto presente, el espacio que encierra los volúmenes de la figura, el espacio que subsiste como vacío entre los volúmenes" (Broncano, 2013, pág. 19), es decir, el espacio en el que el $Y o$ se muestra.

Esta debilidad de ponerse uno mismo como demostración de una continuidad que anima al hombre en el suceso vital organiza el aparecimiento racional de una estancia. La autor representación de nuestras posibilidades históricas busca una permanencia en el tiempo como respuesta a la reflexión sobre la identidad. Al respecto, Heidegger distingue la permanencia sustancial, el mantenimiento de si, en una constancia de sí mismo y considera que, frente a la muerte, no es posible agotar el sentido de sí. Por ello, creemos que la pretensión de la construcción de una identidad otorga sentido a la existencia y la hace superar la vivencia mientras referencia nuestra experiencia del mundo y facilita la constitución de los ejercicios memorísticos y figurativos. Cuando el sujeto se auto nombra, se autor refiere, lo hace para reflexionar sobre su propio acto de nombrar-se o referir-se y no sólo como una expresión de la causalidad de Sí. En este sentido, PaulRicoeur propone, el relato autobiográfico como un símbolo de la integración del tiempo sobre la ipseidad y observa que, quien relata el yo está obligado a emplear la narración adaptándola y configurándola en la reserva de lo histórico, para nosotros esto mismo sucede en el autorretrato. El análisis de esta propuesta de la autor representación pretende encausar una relación que se expresa entre la extensión del tiempo por la memoria y la descripción de esa extensión por el la configuración histórica que se construye, en la propuesta que Paul Ricoeurpone respecto de la Mimesis. De este modo, la imagen es un medio de profundización de la compresión de sí que se trasmite en la cultura por medio de la creación de una historiografía personal en la que el sujeto, para usar un tópico heideggeriano, se espacia, es decir, se pone frente a lo libre y lo abierto. En La mirada del retrato (2000), Jean-Luc Nancy se refiere, a esta condición diciendo que: El retrato no consiste simplemente en revelar una identidad o un «yo». Esto es siempre, sin duda, lo que se busca: de ahí que la imitación tenga siempre primeramente su fin en una revelación en un develamiento que haría salir al yo del cuadro; o sea un «destelamiento». (Nancy, 2006, págs. 15-16).

Nosotros consideramos que el retrato opera el mismo sentido de una doble revelación, la que va del Yo a la comprensión del agente y la que se extiende en el límite de la relación de un Yo con un tercero.Al considerar lo que se está planteando en la producción de la identidad por la imagen, la orientación de una estructura interna del pensar que se exterioriza y la búsqueda de las relaciones entre lo que Ricoeur denomina el ipse y el ídem desemboca en un "texto fotográfico" que se manifiesta como figuración. Este espacio es la caracterización de la reconciliación de lo que se busca y lo que se pierde en la existencia. Sabemos, a partir del texto de Broncano, que Ricoeur encamina su proyecto desde la idea de una examinación de la vida y que estos relatos se organizan en torno a lo que él llama: [...] una función de relevancia que no puede ser considerada como una relevancia privada, sino como una inmersión en prácticas reconocibles. 
Esta forma de relato supone, pues, un yo-espejo que nos relata, o que relata nuestro relato ante la comunidad. Es decir, el relato de la propia vida puede y debe ser contable(Broncano, 2013, pág. 190).

En Tiempo y narración, Paul Ricoeur plantea que la existencia humana permite una experiencia del tiempo que se constituye a sí misma por la experiencia humana que se atraviesa en la validación y el otorgamiento de sentido de esa experiencia por una memoria narrativa que vincula el pasado y el presente como límite de la experiencia. Lo anterior pone a Ricoeur en la lógica agustiniana, según la cual, el tiempo puede aparecer como la tensión que se extiende entre la sensación y el sentido de ésta. Ello le da a la memoria un carácter espacial y hace del relato memorístico o de la figuración autor representacional un espacio limítrofe donde, como lo dice Martin Heidegger: "habla y se oculta un acontecer" (Heidegger, 2009, pág. 23).

El tiempo, en tanto sucesión irreversible, genera que la existencia del hombre se encuentra siempre en el "instante" de su encuentro consigo mismo y su mundo. En este sentido, la instantaneidad, que es el tiempo de la existencia, se convierte en una potencialidad de la trascendencia del tiempo que rompe la condición angustiosa de la constitución histórica del sujeto. El hombre está destinado a hacer de su experiencia histórica la posibilidad de la trascendencia histórica.

Ahora bien, es necesario comprender las tendencias y las fuerzas que, desde el pasado, preparan el presente que late en el hombre. Conocer las vinculaciones que los hechos humanos tienen en el tiempo es parte del impulso de la comprensión de los hechos de la vida del hombre y su destino. El conocimiento histórico del hombre plantea una forma de construcción de pre-visión de la trascendencia que la imagen configura. Si nuestra biografía se construye por la articulación sucesiva de instantes, nuestra existencia es la respuesta a las interrogantes que nos plantea dicha articulación.

La biografía es, de este modo, la mirada de cada hombre frente a sí; la búsqueda personal de su hacerse cargo de la realidad que lo interpela. En el autorretrato nos hacemos cargo de nosotros mismos para construir el horizonte por el que se nos identifica. La vida del hombre es dinámica y ello significa que en ella se fragua el Ser. El sujeto no quiere ser testigo de su propia extinción y, debido a ello, se relata, se imagina, se figura para permanecer. La recuperación de esa condición se expresa en el autorretrato que aparece como un símil de la Memoria narrativa y supone una herramienta de la comprensión desde la cual es posible conjugar nuestra concepción histórica del tiempo.

Es decir, la memoria supone una suerte de enlace entre los sucesos del pasado y nuestra estancia cotidiana en el presente. Nosotros consideramos que la memoria es una alternativa de estudio que ayuda al hombre en el razonamiento de su condición existencial y difiere el sentido que le damos al recuerdo. El recuerdo deviene memoria, en la medida en que la imagen que revela la condición existencial del sujeto se vuelve documento de la vivencia de lo uno en lo otro. El encuentro del aquí en el mundo del hombre que se relaciona con los otros hombres genera una relación próxima de recepción de lo histórico del sujeto que acepta el documento de su rememoración como acontecimiento de sí mismo.

El autorretrato deja claro porque somos lo que somos: la conciencia de la experiencia, la peculiaridad por la que confirmamos nuestro enlace con el mundo que se aloja en la memoria. El alcance de esta facultad dinámica del sujeto es tan amplio que no se somete a la estructura temporal de la existencia sino que la trascienden en virtud de su realización histórico-memo-narrativa por la que adquiere una dimensión archivística de los acontecimientos y su autenticidad.

San Agustín consideró a la memoria como el alma que recuerda y distinguió dos tipos de memoria: sensible e inteligible o negativa y positiva. El Obispo de Hipona considera que la memoria es el presente del pasado y que, en el espacio donde se encuentra el consumo de nuestra historia, se preserva toda especie de imágenes y se evoca todo aquello que se guarda y cuya potencia sólo puede dañarse por el olvido. En la memoria nos adentramos para encontrarnos a nosotros mismos, en ella, volvemos a la experiencia y nos acercamos a los acontecimientos de lo que está por venir. La memoria es, desde la perspectiva agustiniana, la fuerza misma que nos ayuda en la configuración de la realidad y nos actualiza. Siguiendo la lógica de Agustín, Henri Bergson resuelve el problema de las distintas configuraciones de la memoria y postula que ésta puede ser una memoria-hábito o de repetición o una memoria representativa. Para el francés, la primera es psíco-fisiológica y la segunda constituye la propia esencia de la conciencia. De este modo, la memoria representa la continuidad de la persona y fundamenta la conciencia de la duración. 
Bergson, considera a la memoria un aspecto esencial del hombre en cuánto entidad espiritual y afirma que ésta lo conserva de su pasado y lo actualiza en el presente formando el sentido de la tradición. El filósofo francés acuña la concepción de una memoria que fundamenta la existencia de la memoria propiamente psicológica, es decir, una memoria en tanto retención, repetición y reproducción de los contenidos pasados.

Paul Ricoeur, se sitúa en el pensamiento agustiniano y bergsoniano para decir que la narración que trama el historiador es la herramienta cognitiva que permite significar el mundo y que la narración de dichos acontecimiento recordados, en tanto síntesis de lo heterogéneo, es un modo de recuperación de las intenciones, motivaciones, acciones y consecuencias que configuran una trama. Nosotros creemos que el autorretrato puede verse como el resultado de esa trama. De este modo, la trama se vuelve mímesis de una acción y, en el ámbito figurativo, imagen autorreferencial.

Según Ricoeur, en la memoria están presentes todas las vivencias y su acción pretende la conservación de éstas. La rememoración es un modo de recuperación del olvido que hace volver un conocimiento de lo posible o desaparecido. Ricoeur considera a este movimiento imaginario huella, y cree que nace del recuerdo por el cual queremos ser parte del pasado y reconocernos en el presente desde la memoria. Si la memoria permite elaborar una serie de representaciones objetivas de la historia y emparentarlas con la imagen autor representacional, esta imagen adquiere validez en tanto manifiesta el deseo de permanencia. De este modo, en el autorretrato significamos nuestra travesía existencial.

La comprensión del Yo se puede lograr en la composición auto fotográfica porque ella es la representación del espacio que habita nuestra memoria, el lugar en el que asiste frente a nosotros lo vasto. En este sentido, la popularización del autorretrato en la práctica fotográfica, hoy en día, se debe a la disponibilidad técnica de la capacidad de compartir instantáneamente emociones o vivencias por medio de una imagen en la que la simbolización de la experiencia es el dato fundamental de la expresión.

Si tal como lo Susan Sontag:"la necesidad de tener una realidad confirmada y la experiencia mejorada con la fotografía es un consumismo estético al que todo el mundo ahora es adicto".(Susan, 1977), las configuraciones que se hacen de dicha experiencia operan la apertura de un universos de significación desde la que se problematiza la construcción de nosotros mismos.

Lo anterior, nos hace considerar que es necesario rastrear algunos de los códigos culturales y estéticos del género del autorretrato del siglo XXI. En este análisis nos interesa establecer la forma en que el autorretrato, la auto figuración o la autor representación incorporaran a sus prácticas discusivas la memoria y hacen del mensaje fotográfico el espacio de la configuración del Yo por medio de la recuperación de la experiencia. Trama de la identidad estas manifestaciones autor representacionales manifiestan, en distintos niveles, la forma en que los autores expresan o simbolización su propia configuración por la fotografía. Nos interesa revisar algunos de los códigos estéticos que se ofrecen en el desarrollo de la fotografía y vincularlos con un análisis iconográfico de la imagen desde el autorretrato. En este sentido, nos parece importante desarrollar nuestro análisis a partir de la práctica estética de la imagen femenina y, consideramos necesario decir que no pretendemos ignorar las teorías feministas sino que nos interesa, sobre todo, elaborar un análisis de la configuración de la identidad femenina en el autorretrato y algunas de sus expresiones.

Uno de los temas clave en este estudio es la identificación de la existencia de un "estilo femenino especial" que, en la práctica artística del autorretrato fotográfico, nos permite establecer una base teórica en la cual situar los códigos estéticos en los que vinculamos temas como: la negación de sí mismo; la negación de lo femenino; la lucha contra la esencia femenina; lo and rogénico o; el papel de la mujer en el mundo postmoderno etc. Cuando analizamos algunas obras vinculados a la autor representación es necesario comprender que cualquier imagen es, en cierto modo, un autorretrato. Es decir, toda imagen trae consigo la experiencia, las vivencias y el bagaje cultural del agente que la desarrolla. Por el autorretrato, un autor simboliza lo que lo ha hecho experimentarse, el detalle en el que se inscribe a sí mismo. Creemos que el género del retrato en el que el propio artista es el modelo es la forma más universal del presente eterno. En el ámbito femenino, las configuraciones autor representacionales tienen configuraciones específicas y ello nos permite desarrollar un esquema de trabajo desde las simbolizaciones en que éstas se operan en la expresión artística contemporánea.

\section{Discursos femeninos en las obras de artistas contemporáneas}


Si consideramos que en el análisis del autorretrato femenino se construye una tipología general completamente definida, hay algunas preguntas que saltan a la vista: ¿Qué muestran las fotógrafas en sus autorretratos? ¿Qué temas se expresan ellos? ¿Qué ideas intentan difundir?

Una contrastación entre las prácticas masculina y femenina en el autorretrato revela una diferencia fundamental que nos permite ver que los códigos estéticos femeninos incrustados en los autorretratos están vinculados con tres aspectos:

1. La elaboración de una narración documental.

2. La exploración de la identidad

3. La exploración de límites y soluciones a los problemas que excitan a las autoras: enfermedad, condición profesional, etc..

La crítica feminista se asocia con una cuestión de género cuya relevancia aumenta en la segunda mitad del siglo XX y se mantiene en el punto más alto del interés de los científicos hasta el momento. De forma general, el géneroes una representación de la individualidad en términos de las relaciones sociales específicas que se tienen con los otros en un grupo determinado. En la ciencia, el enfoque de género se basa en la primacía de las diferencias biológicas entre lo masculino y lo femenino. En términos culturales, el análisis parte del papel que hombres y mueres juegan en la sociedad.

Según Kitsch, el trabajo con lo repulsivo y aquello que no es perfecto es un tema recurrente en el arte de las últimas décadas. La creatividad femenina se caracteriza por la asunción de una actitud diferente respecto de la comprensión de la fealdad y una tendencia opuesta a la idealización de lo femenino. Por ejemplo, la fotógrafa norteamericana Diana Arbus crea fotografías de personas enfermas o que parecen extrañas gracias a que tienen un aspecto diferente al que se manifiesta en la publicidad y la cotidianidad haciendo que el disgusto doloroso creado en el espacio de su encuadre, atraiga y repela al mismo tiempo. Arbus crea,no un retrato de la sociedad más bien una visión de ésta, es decir, no un retrato, sino un autorretrato a partir de esos rostros ajenos. Cansada de la fotografía de moda y la publicidad de las imágenes perfectas, la norteamericana comenzó su búsqueda de la artística enfocándose en la representación de personas que, en su visión, están más allá de las calles. Según Carol Armstrong, la norteamericana busca retratar la personalidad y establece un contacto psicológico fijando no sólo la cáscara material visible sino el estado interno del sujeto.(Armstrong, 1993)(Carol Armstrong. Biology, Destiny, Photography: Difference According to Diane Arbus. The MIT Press, Vol. 66 (Autumn, 1993), pp. 28- 54).

Otra de las tendencias que hemos podido identificar en torno al arte de la autorrepresentaciónfemenina radica en el énfasis de la distinción entre lo espiritual y lo material. Esta práctica comienza a difundirse a mediados del siglo XX y alcanza su auge en las primeras décadas del XXI en el llamado mercado de masas. Numerosas marcas utilizan a las modelos con una apariencia alejada del estándarmodelísticopara la promoción de sus productos. En sus campañas, estas compañías hacen circularpropaganda masivaque llama a las mujeres a amar su propio cuerpo más allá de su estatura o su complexión. La tendencia de los medios en las últimas décadas muestra un alto nivel de lectura de la realidad en el que se presenta cotidianamente una visión hipertrofiadade la realidad con retratos inquietantes y poco convencionales como los retratos de monstruos de Arbuso, el espacio natural que nos rodea en la vida cotidiana representado en mujeres reales que posan para las revistas de moda. En la cultura moderna, la imagen de lo femenino resulta ser un juego de sentidos definidospor la estética de las fotografas. Una vez descritas algunas tendencias de la expresión autofigurativa del retrato contemporáneo queremos describir más ampliamente la tipología que describimos anteriormente.

\section{Tipología del autorretrato: de la emoción a la problematización de un aspecto social.}

Tal como lo mencionamos anteriormente, en el desarrollo de esta investigación hemos podido distinguir, luego del análisis de una amplia selección de fotografías artísticas, tres tendencias comunes en el autorretrato:

1. La primera tendencia está determinada por una narración documental. Según está idea, una fotógrafa documenta su vida y establece una reacción emocional con lo acontecido en su espacio existencial. Es decir, configura su identidad a partir de los acontecimientos en los que ella misma se construye. Algunos ejemplos de esta expresión se presentan por medio de una "foto-hecho" y elaboran una crónica por medio de la cual, las mujeres desarrollan una comprensión del tema de interés desde la perspectiva femenina.

2. La exploración de la identidad en la fotógrafa-modelo nos acerca a lo que las artistas dicen de sí mismas mientras trabajan en su propia imagen. En este sentido, la imagen expresa deliberadamente la actitud de la autora tanto a nivel corporal como espiritual. 
3. Las artistas que están desarrollando series fotográficas nos ofrecen, a través de secuencia de imágenes, una exploración de los límites y de las posibles soluciones a los problemas que excitan alas autoras y que son propios de la sociedad en general. En estos ejemplos, no hay imágenes aisladas, quienes desarrollan obras fotográficas, en este sentido, exploran un tema a lo largo su trayectoria creativa tal como lo hace Francesca Wood man. En la misma lógica, la de la exploración de los límites y el análisis social, Cindy Sherman hace referencia a su propia imagen para revelar diversos aspectos estéticos.

Analizaremos las series de Francesca Woodman y Cindy Sherman a través del prisma de la época y los fenómenos que las envuelven. Francesca Woodman es un objeto y sujeto de sus composiciones fotográficas al mismo tiempo. Sus autorretratos siempre son investigaciones complejas. Ella misma se plantea la cuestión que quiere desarrollar, construye el cuadro y ofrece a la lectura, dejando al espectador el derecho de crear una conclusión independiente sobre que vio y percibió. Para Woodman, el material y su forma son primordiales y en su interacción surge el mensaje transmitido a través de la imagen (Tejeda, 2013, pág. 119).

Como cualquier otro material, Woodmanutiliza su cuerpo para llevar a cabo una autoexploración y busca vínculos entre su propio cuerpo y los objetos delentorno. El cuerpo es siempre un ser vivo, en movimiento, suave, se mueve demasiado rápido para estar fuera de foco y se contrasta con los materiales fríos y densos que circundan su representación. Sin embargo, la composición que se coloca alrededor de este cuerpo lo absorbe por completo, sin dar la oportunidad de dividir la imagen en planos.

En From the Eel Series, el espectador está mirando a un ser humano y no a la mujer desnuda que puebla la imagen. Ésta es la especificidad de los autorretratos fotográficos de Francesca Woodman. La imagen capta la emoción, el estado mental y la situación de la autora en el nivel de la lectura. Por la imagen, Woodman crea un mensaje fotográfico con la ayuda de un cuerpo femenino. Sin embargo, este es un material, no un objeto en la composición fotográfica.En tanto autor, Woodman está presente en sus propias imágenes, su emoción es transmitida a través de obras exclusivamente personales. La manifestación del propio Yo en un autorretrato se representa a través de la propia emoción

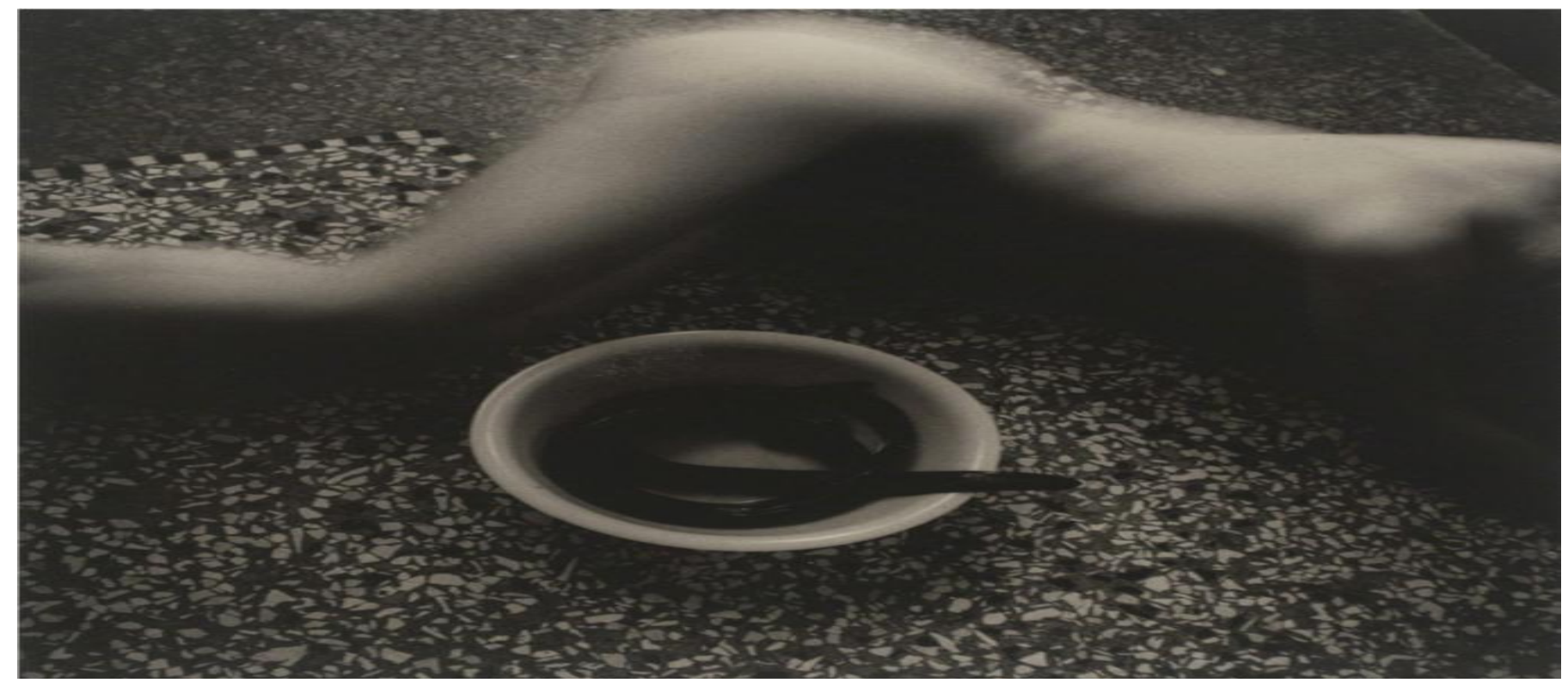

Ficha tecnica: From the Eel Series, Rome, 1977-1978, Gelatin silver print, printed c. 1977-1978, 5 3/4 × 5 3/4 in; $14.6 \times 14.6 \mathrm{~cm}[\mathrm{https} / /$ www.artsy.net/artwork/francesca-woodman-from-the-eel-series-rome-1 fecha de consulta 13.08.2018]

Los trabajos de Cindy Sherman, a diferencia de las obras de Woodman, permiten al el espectador ver los retratos de todas las mujeres de la época a la vez con excepción de la autora. No podemos hacer una conclusión sobre cómo se ve Sherman a sí misma:el color y la longitud de su cabello; las características de su figura;sus preferencias y el estilo de la ropa nos impiden identificarla Sherman pareciera perderse en una imagen femenina global pero, paradójicamente, nos dice, esta soy Yo.La fotógrafa norteamericana no dice absolutamente nada personal sino que, adoptando un sinfín de clichés, captura la historia de una mujer, la forma en que la mujer puede verse a sí misma o postula la proyección de la manera en que debe verse una mujer ante los ojos de otras mujeres. 
El trabajo de Sherman es el trabajo de la construcción de una propuesta crítica que hace de la representación femenina el reconocimiento de su identidad.

Sherman ilustra a las mujeres exagerando y llevando hasta el kitsch las imágenes de las mujeres estadounidensesque encontramos en la vida cotidiana. Utiliza la cámara, el maquillaje, el vestuario y el escenario, para recrear ilusiones comunes o "instantáneas" icónicas que unen varios conceptos de celebridad pública, confianza (desconfianza) en sí mismo, entretenimiento y otras situacionesde la vida cotidiana.

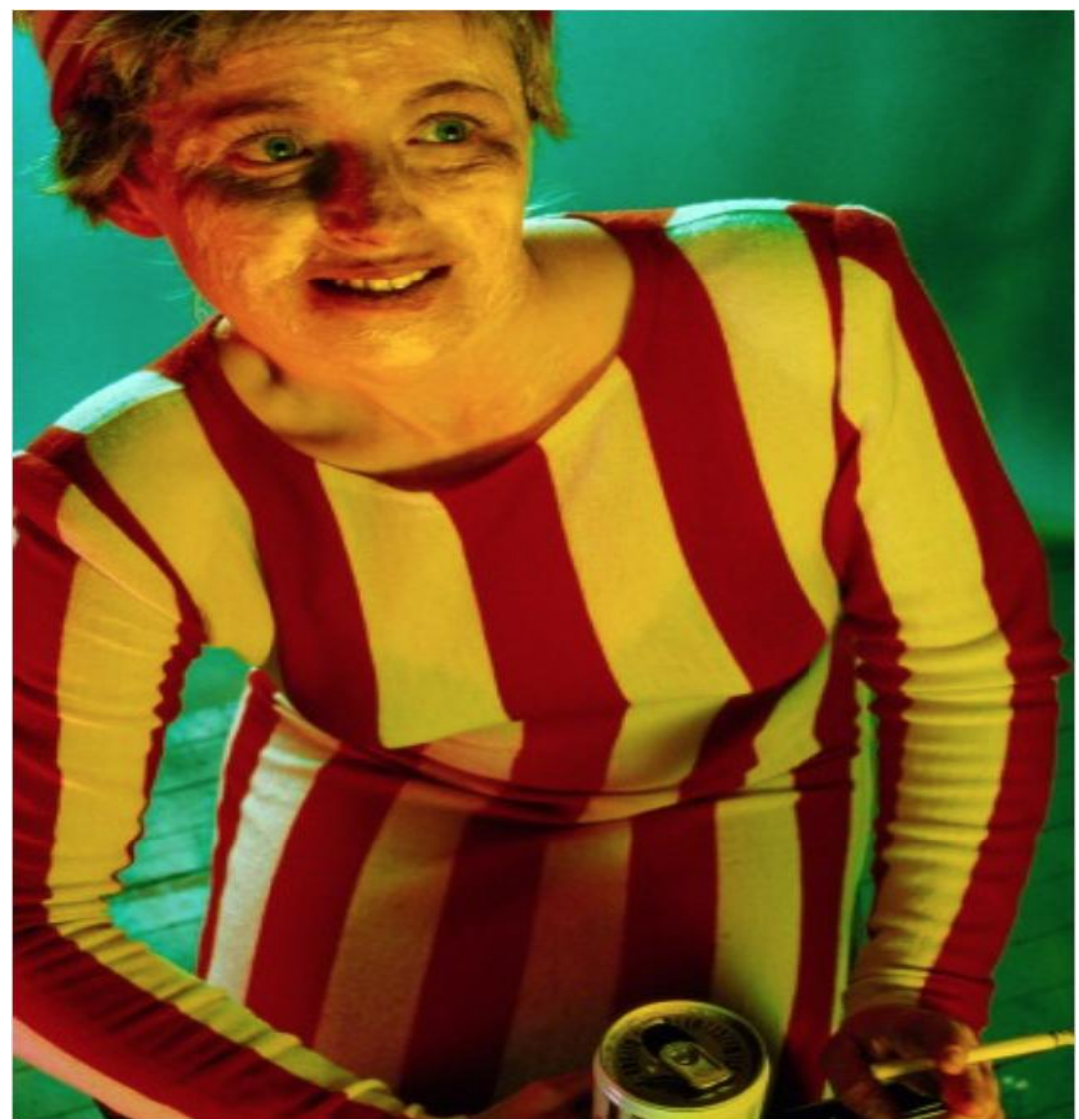

Ficha tecnica: Untitled \#132. 1984

[https://www.moma.org/interactives/exhibitions/2012/cindysherman/gallery/3/\#/7/untitled-132-1984/ fecha de consulta 13.08.2018]

El punto es la desaparición específica del sujeto en las obras de Sherman y la existencia de solo un objeto,figuración de la mujer, una mujer como modelo colectivo cuyos papeles se desarrollan de serie a serie, dejando la personalidad de Sherman afuera y dejando en el encuadre solo el cuerpo de Sherman, que trabaja como maniquí para crear imágenes complejas.Existen múltiples series fotográficas donde Cindy Sherman está actuandodisfrazadacon la intención de demostrar que una mujer moderna no tiene su propia cara, simplemente carga una máscara impuesta por una cultura pop en un rango que va desde la representación de un ama de casa humilde hasta una mujer frívola y aventurera.

\section{El autorretrato digital: itinerario de cuatro artistas nóveles salmantinas.}

Nuestro estudio muestra una serie de fotografías que nos han permitido utilizar y valorar la aplicación de diversas técnicas en la creación de autorretrato fotográfico: la utilización del espejo o temporizador para el disparo automático;la capturando la propia imagen como expresión de la condición situacional de la existencia; el uso de la cámara como mecanismo para reafirmar la pertenencia a laprofesión; el retrato de la presencia del autor a través de sombras, siluetas o indicios del autoren el encuadre y; la imagen en la que la fotógrafo actúa como modelo. Todas estas expresiones están vinculadas, en diversos modos a la tipología que describimos en el apartado anterior y a continuación describimos algunas de estas características en el la fotografía de cuatro artistas. En la primera fotografía, Marisol Salinas nos presenta Múltiple. Lo primero que llama la atención en la auto-figuración es la condición fragmentaria del discurso en el cual se inscribe la representación de esta artista. La imagen, además viene acompañada de un cifra que nos permite describir la condición inacabada del sujeto: "Fragmentada. 
Como siempre. Del ser a no ser. De la mañana a la noche. Como un papel doblado en diez". El tránsito de la estancia existencial revela en la fotografía una condición que manifiesta aquello que resuena desde la perspectiva nietzscheana en el pensamiento de Gianni Vatimo y nos permite ver que el sujeto nunca es una entidad estable, homogénea o completa. El filósofo italiano asegura en el apartado "Muerte o crepúsculo del arte" de El fin dela modernidad (1985) que:

[...] uno de los criterios de valoración de la obra de arte parece ser en primer lugar la capacidad que tenga la obra de poner en discusión su propia condición: ya en el nivel directo y entonces a menudo bastante burdo; ya de una manera indirecta, por ejemplo, como ironización de los géneros literarios, como poética de la cita, como uso de la fotografía entendida no en cuanto medio para realizar efectos formales, sino en pura y simple operación de duplicación. (Váttimo Gianni, 1990, pág. 51)

En este sentido, el de la manifestación de la inestabilidad subjetiva, salinas revela una configuración que nos revela la condición mística que los pitagóricos describían en la Tetractis, el sujeto es la suma de sus fragmentos, la configuración de la subjetividad no está completa hasta que se unen los cuatro puntos que, según lo permiten ver la cifra y la configuración de la mirada en el autorretrato, bien pueden ser los puntos cardinales. La fotografía de Salinas, muestra desde nuestra perspectiva la suma de los fragmentos, la condición inacabada del sujeto y la formación de una identidad desde los diversos rastros en que se operan las búsquedas.

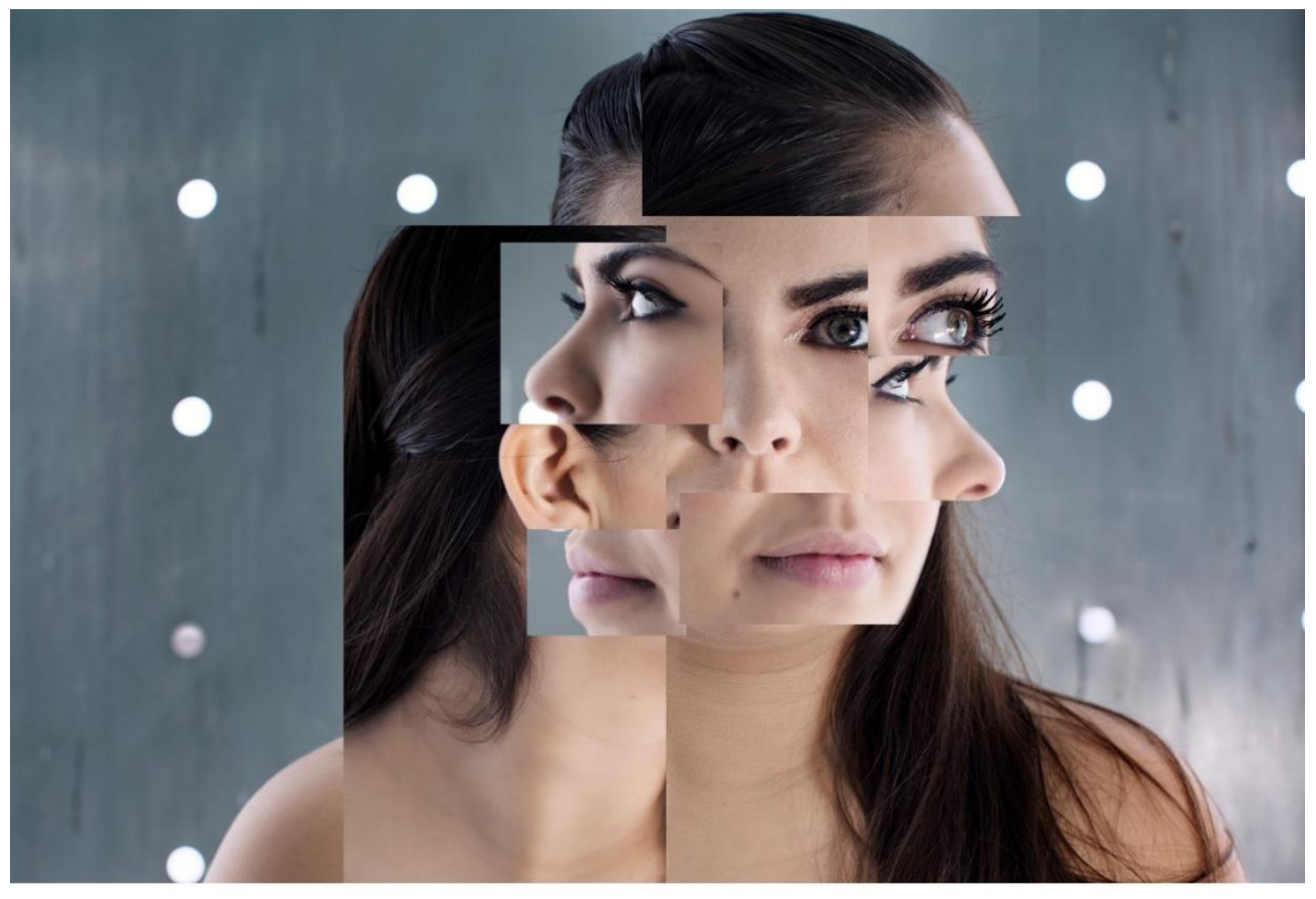

Múltiple. Marisol Sánchez Salinas, 2018.

-Fragmentada. Como siempre. Del ser al no ser. De la mañana a la noche. Como un papel doblado en diez.

La segunda fotografía que analizamos en este trabajo es obra de Rosa María Morales Valdivia y se titula cuervo. La referencia a la obra de Edgar Allan Poe resuena inmediatamente en la imagen; los tonos púrpura en que se muestra el encuadre que van mutando en la lectura hacia el negro vinculan, casi de inmediato al receptor, con la poética romántica. En la imagen, además se agrega una frase del poema del escritor norteamericano. En términos culturales, es importante señalar que nosotros somos lo que leemos, nuestra cultura es la manifestación de una dinámica intercultural en la que se operan sentidos desde la comprensión o sunción de diversos discursos y formas de expresión con las que estamos en contacto. Jesús Camarero, alude a esta condición de vinculación y alejamiento de la literariedad con el término de Travesía Textual Comparada. En este sentido, Camarero alude a una propiedad de la intertextualidad a la que define en los siguientes términos: La intertextualidad aporta información sobre el modelo literario (qué autores, qué obras) y el funcionamiento de las referencias culturales (cómo se construye la relación entre unos y otros) de una época. 
Las lecturas se acumulan en la memoria y luego pasan a la escritura, en las que se representan las referencias guardadas y admiradas que constituirán, en una nueva obra, el objeto de otras lecturas futuras.(Camarero, 2008, pág. 27).

Nosotros consideramos que, en tanto manifestación discursiva afin a la representación, la fotografía puede asumir los mismos gestos que la literatura y que una fotografía es el resultado de la forma en que la identidad se construye desde aquello que se aloja y expresa esa condición de vinculación y apropiación de una obra desde la lógica de una relectura o interpretación. Si asumimos aquello que hemos referido respecto de Vattimo al hablar de la cita o la modificación de diversos ámbitos discursivos en la creación de nuevas poéticas, lo que Rosa María Morales no permite ver es la configuración de su identidad desde la vinculación con la literatura de Poe.

Ahora bien, si como lo afirma Jesús Camarero: "Una obra es la síntesis global de significaciones alojadas en el interior del texto $\mathrm{T}$ (macrotexto) y relacionadas entre sí en virtud de un ser capaz de concatenar sus componentes textuales t (microtextos)"(Camarero, 2008, pág. 42), la obra de Morales manifiesta la simbolización de su identidad desde aquello a lo que, en su dinámica cultural, se adhiere. La obra de Poe es, en el caso de la fotgrafía de Morales Valdivia el acicate desde el cual es posible leer la construcción de lo que ella quiere ser en el momento en que se inscribe.

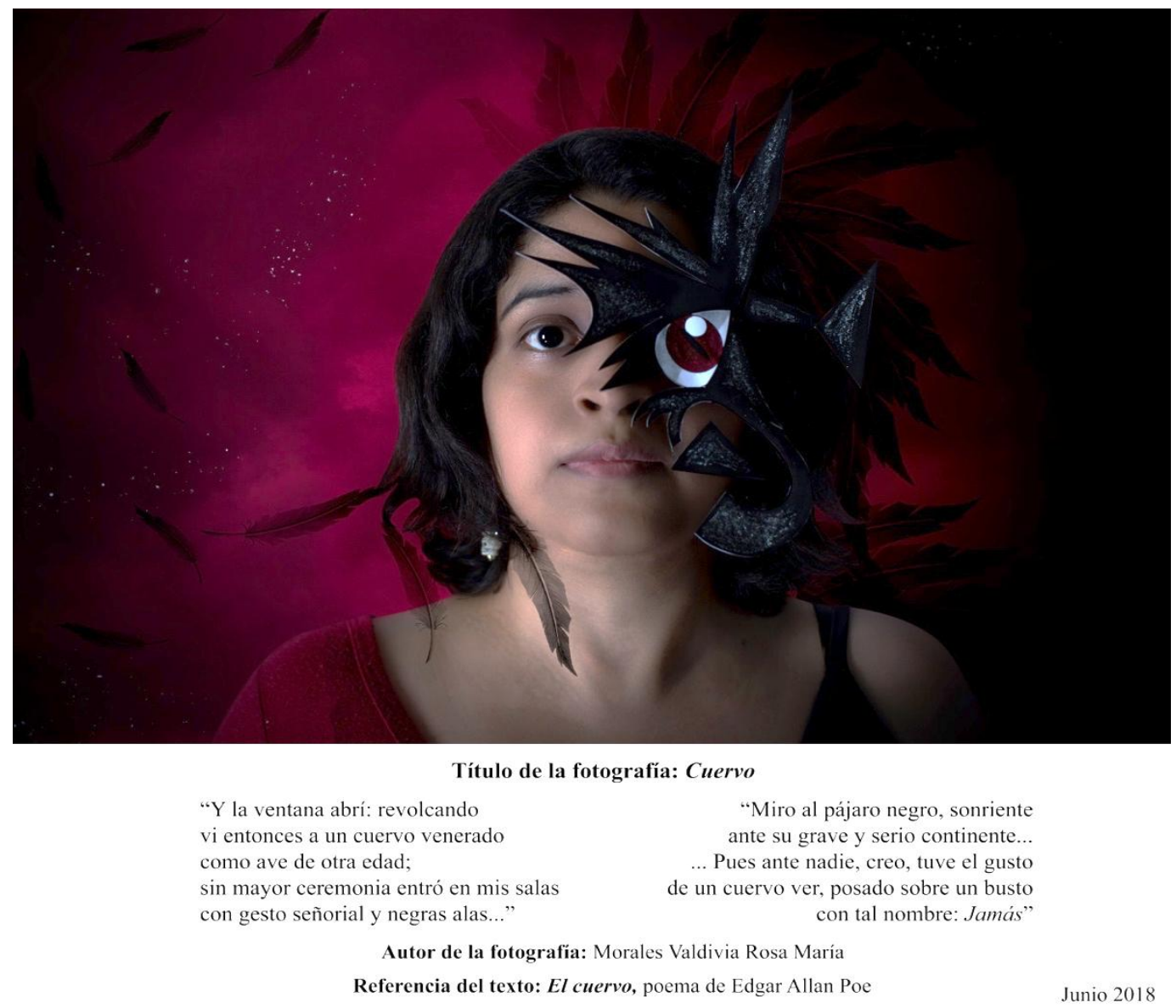

La tercera imagen que presentamos en este trabajo es un autorretrato de Enya Flores Gutiérrez titulado DentFuroe. De la misma manera que en los casos anteriores la imagen viene acompañada de un ancla que nos permite identificar el sentido de la imagen y opera una significación vinculada al dolor, a la problemática de la condición enfermiza de la autora y a la transformación de ese dolor en un motivo estético: "Me gustaría ser valiente. Mi dentista asegura que no lo soy..." resuena la frase borgiana en el pie de foto del montaje de Flores.

Es común decir que la expresión artística en general tiene una finalidad catártica. Aristóteles afirma en el Arte poética que ese es el sentido de la representación. Más tarde los epicureistas describen una de las características del arte como la manifestación de un estado de ataraxia o serenidad del alma, la supresión del dolor, la transformación de éste hacen que el sujeto transite del dolor a la dicha o viceversa, peripecia de la existencia que nos hace movernos indefinidamente del no ser al ser. 
La imagen de Enya Flores revela una peripecia que se opera desde la necesidad de estar bien y tiene como mecanismo el sufrimiento que la cirugía trae consigo. Enya parece haber encontrado, en su enfrentamiento con el dolor que supone el furor dental, el mecanismo de su expresión, el acicate de su reconocimiento. La radiografía que desdibuja la sonrisa de la autora aparece en la imagen como un sinécdoque de la experiencia que configura a la autora y parece decirnos que todo tránsito es complejo, minucioso, quirúrgico, que uno sólo es en la medida que transita sus miedos, sus dolores y sus imperfecciones y las transfigura. En el caso de Flores, el rastreo de la identidad depende necesariamente de la manera en que ella recupera su experiencia del dolor y lo transforma en el símbolo de aquello a lo éste le ha conducido. En La imaginación simbólica, Gilbert Durand considera que el sentido del símbolo es lograr lo que llama: "la aparición de lo inefable"(Durand, 1968, pág. 14) Enya Flores logra, por medio de su expresión revelarnos ese misterio y lo hace desde la transfiguración de lo que le aterra.

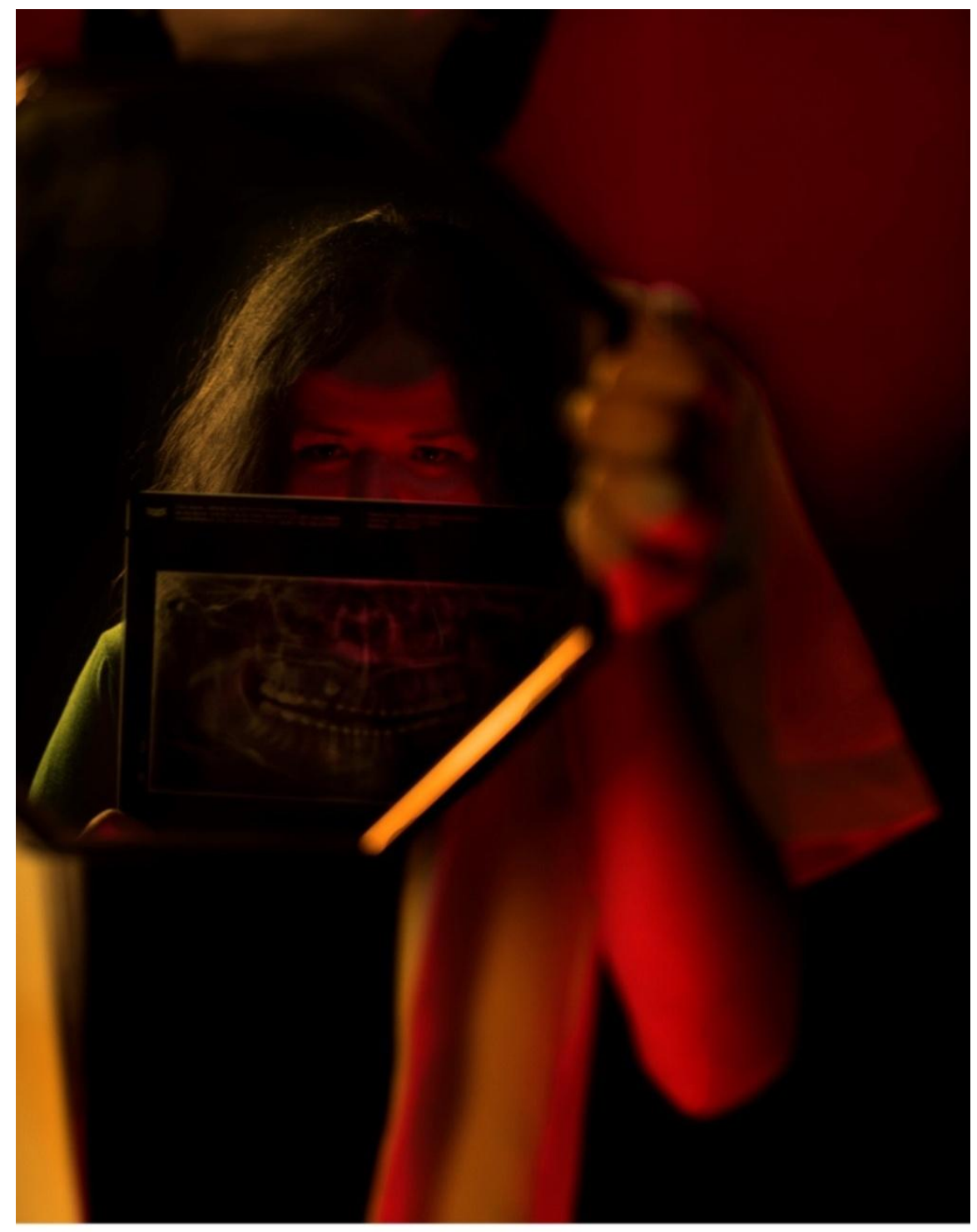

DentFuroe. Enya Flores Gutiérrez, 2018

"Me gustaría ser valiente. Mi dentista asegura que no lo soy..." (Jorge Luis Borges)

Jezabel Guerrero Ledezma nos toma por asalto con Intruso. La fotografía parece indicarnos que Guerrero se siente alejada del discurso fotográfico pero lo acecha, pretende contenerlo su irrupción contrasta con el carácter metadiscursivo de su expresión y nos permite ver su gesto irónico que se completa con la cita de Jorge Volpi que acompaña el texto: 
"Aspiré a volverme nómada, moverme sin cesar, vivir lejos de todas partes. Comprobar que inclusoaquí soy un intruso" Jorge Volpi. Si como sostiene Wayne C. Booth, la ironía consiste "en ver algo que socava las claridades, abre perspectivas del caos, o libera destruyendo todo dogma o destruye al revelar el indescriptible chancro de negación en el corazón de cada afirmación (Booth, 1974, pág. IX), el autorretrato de Jezabel Guerrero nos permite ver que ella quiere definirse en la medida que la fotografía aparece en su horizonte personal y su configuración identitaria. La cámara es una extensión de su mirada, por eso su visión se centra en ella y parece cerrar su discurso quitando dinamicidad a la lectura de la imagen. Sin embargo, lejos de cerrar el simbolismo de su expresión, ésta se hace más intensa al simbolizar su búsqueda aparentemente impropia.

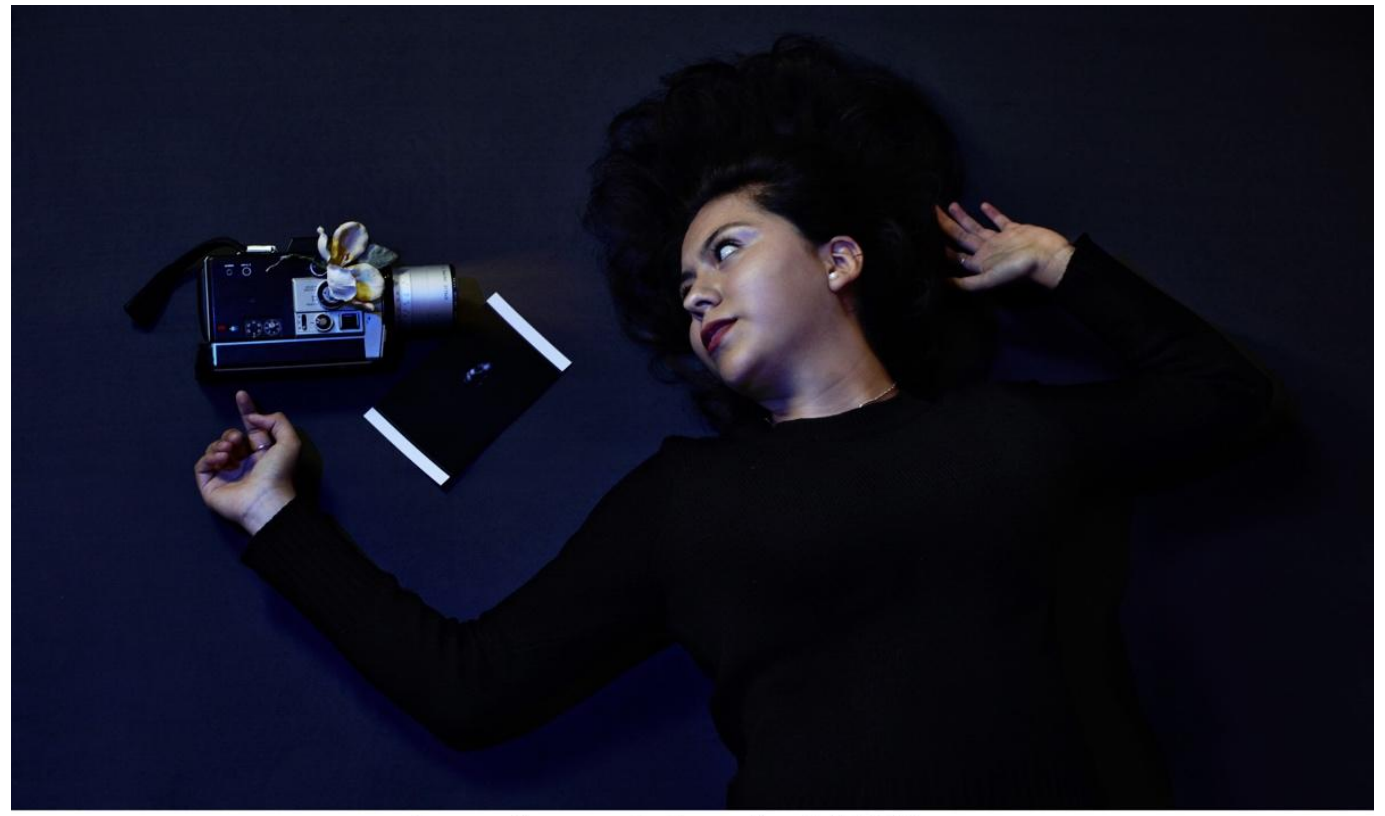

Intruso, Guerrero Ledesma Jezabel,2018.

“Aspiré a volverme nómada, moverme sin cesar, vivir lejos de todas partes. Comprobar que incluso aqui soy un intruso" Jorge Volpi.

En $S / Z$ (1970), Roland Barthes considera que: "la ironía desempeña el papel de un anuncio y en consecuencia destruye la multivalencia que podría esperarse de un discurso citacional”(Barthes, 1980, pág. 36), Jezabel hace propias las referencias con que se vinculay por eso es posible identificar su configuración personal en ellas en la medida en que las alude en su composición y nos muestran, como en el caso de Diane Arbus pero si la sordidez de la norteamericana, la búsqueda de si desde la cámara.

Jezabel Guerrero se revela a sí misma mientras se encuentra en un cuadre que, por su movimiento se vuelve su espacio de significación, el sentido de su experiencia. Su encuentro con la cámara nos ofrece la configuración de una estancia identitaria en la que, irónicamente, no termina de encontrarse, tránsito, destino, movimiento hacia ella desde ella misma que se vuelve búsqueda fija de su propia configuración.

\section{Conclusión}

Acercarse a la comprensión de los discursos en los que se inscribe la autrorepresentación femenina resulta complejo, no sólo por lo distendido de la práctica sino, sobre todo, por las preocupaciones que dejan ver en la construcción de su identidad las mujeres. La mirada desde la que se opera la configuración de su identidad que van desde lo más frívolo de la expresión de su identidad hasta la configuración de un sentido existencial en el que problematizan sus expectativas, sus padecimientos o bien, las formas en que se legitiman desde la producción artística en un mundo que las absorbe. En este sentido, hemos querido evaluar la posición desde la que mujer simboliza su existencia y diseña una figuración que le permite entrar en contacto consigo misma, con sus intereses y reticencias. Lo que nos ha importado es reflexionar sobre la condición óntica del símbolo en el que la mujer deja ver, desde la implicación de su figura en el símbolo, lo que ella es, la forma en que ella misma se observa y la redefinición que ofrece de sí por medio de un discurso en el que se vislumbra una teleología de la feminidad. 
Para nosotros, como para quienes han participado en este artículo, lo más importante era definir la práctica del autorretrato con la formulación de una posición que, en un solo movimiento, permita medir la experiencia de las fotógrafas y las implicaciones vitales que dicha experiencia tiene en la configuración discursiva que nos presentan. Hemos podido constatar que las preocupaciones que las mujeres tienen respecto de la manera en que se simbolizan o figuran están asociadas a una lectura específica de su experiencia que nos permite adentrarnos a la comprensión de lo que para ellas significa ser mujer. Esta definición nos hace comprender que la autorrepresentación femenina nos acerca a la comprensión de lo que nosotros mismos somos desde su visión y la obturación de sí mismas.

\section{Bibliografía}

Armstrong Carol. Biology, Destiny, Photography: Difference According to Diane Arbus. The MIT Press, Vol. 66 (Autumn, 1993), pp. 28- 54.

Barthes, R. (1980). S/Z. México: Siglo XXI.

Booth, W. C. (1974). A rhetoric of irony. Chicago: the Universy of Chicago Press.

Broncano, F. (2013). Sujetos en la niebla: Narrativas sobre la identidad,. Barcelona: HERDER.

Camarero, J. (2008). Intertextualidad, redes de textos y literaturas transversales en dinámica cultural. Barcelona: Anthropos.

Durand, G. (1968). La imaginación simbólica. Buenos Aires: Amorrortu.

Heidegger, M. (2009). El arte y el espacio,. Barcelona: HERDER.

Nancy, J. L. (2006). La mirada del retrato. Bueno Aires: Amorrortu.

Sontang, S. (2005). Sobre la Fotografía, Bogotá: Alfaguara

Susan, S. (1977). Fotografía y redes sociales: el consumismo estético y la violencia de la fotografía.JUS Revista digital.

Tejeda Martin, Isabel (2013) Francesca Woodman, una artista escasamente modernista. Revista de Instituciones, Ideas y Mercados No 59, pp. 117-136

Váttimo Gianni, C. H. (1990). El fin de la modernidad. (A. L. Bixio, Trad.) Barcelona: Gedisa. 